\title{
Melanocyte-specific gene 1 promotes melanoma progression by enhancing the expression of Bcl-2
}

\author{
HUI ZHAO ${ }^{1,2^{*}}$, GUOSHENG WU $^{3^{*}}, \mathrm{JI}_{\text {ZHU }}{ }^{* *}$, MENGYAN SUN $^{1 *}$, YUCHONG WANG $^{1}$, \\ YONGJIE FAN ${ }^{1}$, KAI WU $^{1}$, HONGDA BI $^{1}$, HAIYING DAI $^{1}$, CHUAN LV $^{1}$ and CHUNYU XUE ${ }^{1}$ \\ ${ }^{1}$ Department of Plastic Surgery, Changhai Hospital, Shanghai 200433; \\ ${ }^{2}$ Department of Plastic Surgery, The Second Sanatorium of Jinan Military Region, Qingdao, Shandong 266000; \\ ${ }^{3}$ Department of Burn Surgery, Changhai Hospital, Shanghai 200433, P.R. China
}

Received November 24, 2015; Accepted April 28, 2017

DOI 10.3892/ol.2017.7592

\begin{abstract}
Malignant melanoma is a class of highly malignant tumors derived from melanocytes. At present, the dysregulated gene expression involved in the progression of melanoma has attracted much attention. In the present study, the gene expression profile of human melanoma tissue was screened using a cDNA microarray, and it was identified that melanocyte-specific gene $1(M S G 1)$ was significantly overexpressed in melanoma tissue compared with paired nevus tissues. The overexpression of MSG1 in melanoma was subsequently confirmed using immunohistochemistry in a set of melanoma tissues. It was additionally identified that the overexpression of MSG1 may promote cell viability and inhibit cell apoptosis in human melanoma A375 cells, thus promoting melanoma progression. Mechanistically, following screening of the expression of apoptosis-associated proteins, MSGI was demonstrated to enhance the expression of the apoptosis inhibitor B-cell lymphoma 2 (Bcl-2) to inhibit melanoma cell apoptosis. Therefore, it was concluded that the overexpression of MSGl inhibits apoptosis by enhancing Bcl-2 expression in malignant melanoma, thus promoting melanoma progression.
\end{abstract}

\section{Introduction}

Malignant melanoma, a class of highly malignant tumors derived from melanocytes, and is a type of skin cancer with the highest metastasis and mortality rate (1-3). The cure

Correspondence to: Professor Chunyu Xue or Professor Chuan Lv, Department of Plastic Surgery, Changhai Hospital, 168 Changhai Road, Yangpu, Shanghai 200433, P.R. China

E-mail: xcyfun@sina.com

E-mail: drlvchuan@163.com

*Contributed equally

Key words: melanocyte-specific gene 1, melanoma, cell viability, apoptosis, Bcl-2 rate of early melanoma may be $>90 \%$ when it is surgically resected (1-3), while metastatic malignant melanoma often requires chemotherapy, radiotherapy, targeted therapy, immunotherapy or other kinds of combination therapy. Current therapeutic interventions for metastatic melanoma are not sufficient, and the 5-year survival rate is $<20 \%$ (1-3). Therefore, understanding the molecular mechanisms of melanoma pathogenesis and identifying novel potential therapeutic targets are of importance for the prevention of malignant melanoma and the development of interventions (4-6).

Identification of the dysregulated genes in cancer tissues is important in the study of cancer biology. Gene expression microarrays have been applied in the high-throughput profiling of gene expression in number of types of cancer $(7,8)$. In malignant melanoma tissues, a set of genes were identified to be dysregulated compared with normal tissues, and were demonstrated to be associated with processes involved in the carcinogenesis and progression of melanoma, including cell growth, cell cycle progression, apoptosis, cell migration and metastasis $(9,10)$. Furthermore, several of these genes were identified to be associated with the prognosis, survival, and responses to chemotherapy of patients with melanoma $(11,12)$. However, identification of dysregulated genes in melanoma tissues and their roles in cancer development remain an ongoing process in the study of melanoma biology.

Melanocyte-specific gene 1 ( $M S G 1$; also known as $\mathrm{Cbp} / \mathrm{P} 30$-interacting transactivator with Glu/Asp-rich carboxy-terminal domain 1) is a transcriptional cofactor that interacts with CREB-binding protein/p300 and modulates the transcription of a set of downstream genes $(13,14)$. Previous studies have identified that MSGl is an important factor in the differentiation and pigmentation of melanocytes. For example, MSG1 may promote the synthesis of melanin, thus enhancing melanogenesis in melanocytes $(15,16)$. However, the roles of MSG1 in the carcinogenesis and progression of malignant melanoma require additional investigation and elucidation.

In the present study, in order to determine the dysregulated gene expression present in melanoma, the gene expression profiles of human melanoma tissues were screened using a cDNA microarray, and compared with the expression profiles of nevus tissues. MSG1 expression was identified to be significantly overexpressed in melanoma tissues. The overexpression 
of MSG1 in melanoma was subsequently confirmed using immunohistochemistry (IHC) in a set of melanoma tissues. The present study aimed to further examine the roles of MSG1 in the carcinogenesis and progression of malignant melanoma cancer biology, so as to elucidate novel molecular mechanisms underlying melanoma development and potential therapeutic targets for treatment.

\section{Materials and methods}

Clinical melanoma specimens. Human malignant melanoma tissues and melanocytic nevus tissues (surgically resected and later histopathologically diagnosed as benign) were obtained from patients with melanoma during surgery, and diagnosed by pathological validation. A total of 10 patients with nevus and melanoma tissues examined by pathology and without other skin diseases from the Changhai Hospital (Shanghai, China) were included in the study, including 7 male and 3 female patients with a mean age of 48 (age range, 36-65). Ten nevus and matched melanoma tissue samples were obtained between September 2005 and September 2008. All samples were snap-frozen in liquid nitrogen until examination. All human samples were collected with the written informed consent of the patients, and use of human tissues was approved by the Institutional Research Ethics Committee of the Second Military Medical University (Shanghai, China).

Cell culture and transfection. The human malignant melanoma A375 cell line was obtained from the American Type Culture Collection (Manassas, VA, USA) and cultured in DMEM (PAA; GE Healthcare, Chicago, IL, USA) with $10 \%$ fetal bovine serum (FBS) (GE Healthcare, Chicago, IL, USA), under $37.5^{\circ} \mathrm{C}$ and $5 \% \mathrm{CO}_{2}$. Cells were transfected with small interfering (si)RNAs using INTERFER in ${ }^{\circledR}$ reagent (Polyplus-transfection SA, Illkirch, France) according to the manufacturer's protocol, and transfected with MSG1 expressing plasmids (constructed using a pcDNA 3.1 vector) (Invitrogen; Thermo Fisher Scientific, Inc., Waltham, MA, USA) using JetPEI ${ }^{\circledR}$ reagent (Polyplus-transfection SA) following the manufacturer's protocol, and confirmed by western blot analysis, in order to induce MSG1 overexpression. The siRNA target sequences for human $M S G 1$ gene were 5'-UAGCAGCACAUCAGUCGAAUA-3' (sense) and 5'-CCC AAUAUUGUCAAUUAUUUA-3' (antisense), and the negative control siRNA sequences were 5'-UCUCCGAACGUG UCACGUTT-3' (sense) and 5'-ACGUGACACGUUCGGAGA ATT-3' (antisense). siRNA duplexes were transfected at a final concentration of $10 \mathrm{nM}$.

cDNA microarray assay. The Affymetrix GeneChip Human Genome U133 Plus 2.0 array assay was performed by Shanghai Bohao Industrial Co., Ltd., Shanghai, China. In brief, $5 \mu \mathrm{g}$ total RNA samples from melanoma tissues and paired nevus tissues were reverse transcribed into cDNA for use in the microarray, as previously described (17). Hybridization was performed overnight using a micro-circulation pump (Atactic Technologies, Inc., Houston, TX, USA), and images were collected and quantified (17). The differentially detected signals were gathered and presented.
Reverse transcription-quantitative polymerase chain reaction (RT-qPCR) analysis. Total RNA, sourced from patient tissues, was extracted using TRIzol reagent (Invitrogen; Thermo Fisher Scientific, Inc.) following the manufacturer's protocol. RT-qPCR analysis was performed using a SYBR RT-PCR kit (Takara Bio, Inc., Otsu, Japan) and LightCycler (Roche Diagnostics, Basel, Switzerland). The primer sequences for $M S G 1$ were 5'-GGC GGCACCACCATGTACCCT-3' (sense) and 5'-AGGGGCCGG ACTCGTCATACT-3' (antisense); the primer sequences for Bcl-2 were 5'-GGTGGGGTCATGTGTGTGG-3' (sense) and 5'-CGGTTCAGGTACTCAGTCATCC-3' (antisense); and the internal control b-actin sequences were 5'-GGCGGCACCACC ATGTACCCT-3' (sense) and 5'-AGGGGCCGGACTCGTCAT ACT-3' (antisense). The PCR cycle conditions were $95^{\circ} \mathrm{C} 15 \mathrm{sec}$, $55^{\circ} \mathrm{C} 30 \mathrm{sec}, 72^{\circ} \mathrm{C} 30 \mathrm{sec}$ for 45 cycles, and three independent experimental repeats were performed. The relative expression level of gene mRNAs was normalized to that of internal control $\beta$-actin by using $2^{-\Delta \Delta \mathrm{Cq}}$ cycle threshold method (18).

Cell viability analysis. The cell viability of transfected A375 cells was examined by the MTT method. Briefly, cells $(10,000)$ were seeded into 96-well plates, cultured in DMEM with $10 \%$ FBS, and transfected as described. Control cells were transfected with empty pcDNA 3.1 vectors. At the indicated time points $(0,48$ and $96 \mathrm{~h})$, cell culture medium was replaced by fresh medium containing $0.5 \mathrm{mg} / \mathrm{ml} \mathrm{MTT}$. Cells were then incubated at $37^{\circ} \mathrm{C}$ for $2 \mathrm{~h}$, and the MTT-containing medium was then replaced by $0.1 \mathrm{ml}$ of dimethyl sulfoxide to dissolve the formazan (Sigma-Aldrich; Merck KGaA, Darmstadt, Germany). The absorbance in each well was detected at $570 \mathrm{~nm}$.

Apoptosis analysis. Melanoma cells were transfected for $48 \mathrm{~h}$ and cell culture medium was subsequently replaced by serum-free medium (DMEM; PAA; GE Healthcare). At the indicated time points $(0$ and $48 \mathrm{~h})$, cells were harvested and apoptosis was detected using a Calbiochem ${ }^{\circledR}$ Annexin V-FITC Apoptosis Detection kit (Merck KGaA) according to the manufacturer's protocol, and a FACSCalibur flow cytometer (BD Biosciences, Franklin Lakes, NJ, USA). The Annexin V-positive cells were regarded as apoptotic.

IHC. MSG1 expression in melanoma tissues was examined by IHC. In brief, tissues were fixed with formalin and embedded in paraffin, and then sectioned to make tissue sections $(4 \mu \mathrm{m}$ thick), which were deparaffinized in xylene for $20 \mathrm{~min}$ and rehydrated in graded ethanol $(95,85,75$ and $50 \%$ for 5 min each). Endogenous peroxidase activity was blocked by a 30 min incubation in $3 \% \mathrm{H}_{2} \mathrm{O}_{2}$ in $\mathrm{PBS}$, and antigen retrieval was performed in $10 \mathrm{mM}$ citrate buffer ( $\mathrm{pH}$ 6.0) by heating to boil for $5 \mathrm{~min}$. The anti-MSGl primary antibody (cat no. ab87978; Abcam, Cambridge, UK) was diluted 1:500 and incubated at $4^{\circ} \mathrm{C}$ overnight. The secondary antibody was horseradish peroxidase-conjugated goat anti-mouse IgG secondary antibody (cat no. ab97040; Abcam, Cambridge, UK) in 1:1,000 dilution for use and in incubation at $4^{\circ} \mathrm{C}$ for $2 \mathrm{~h}$. Immunostaining was visualized using a 3,3'-diaminobenzidine staining kit (Dako; Agilent Technologies, Inc., Santa Clara, CA, USA) and analyzed using HistoFAXS system and mean DAB staining intensity was calculated using Histoquest 
A

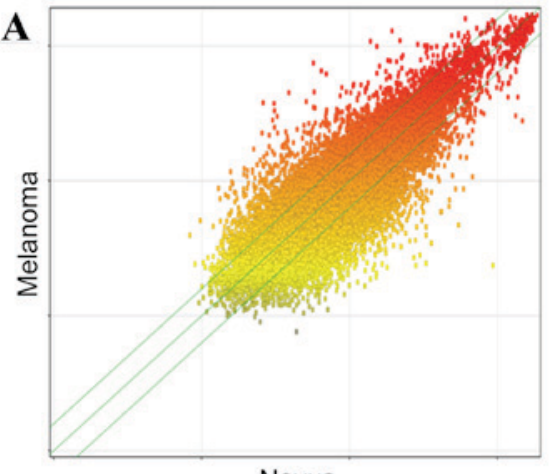

Nevus
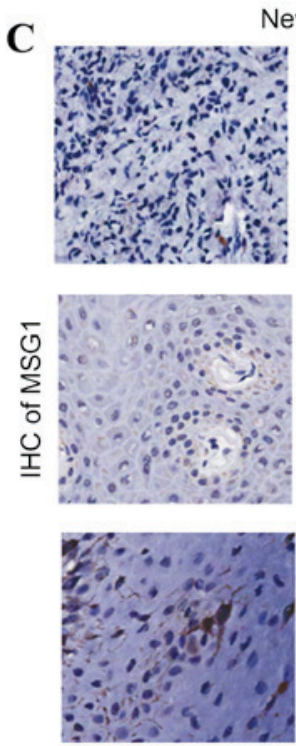

Nevus
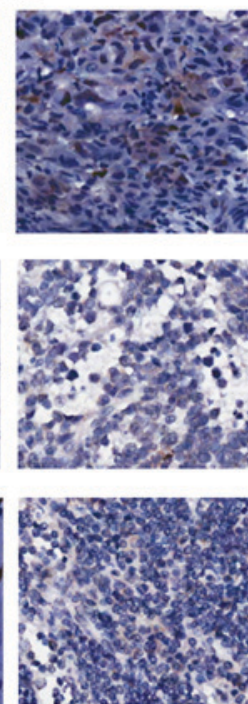

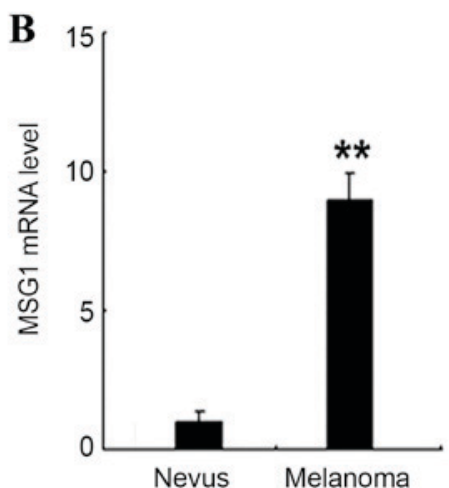

Melanoma
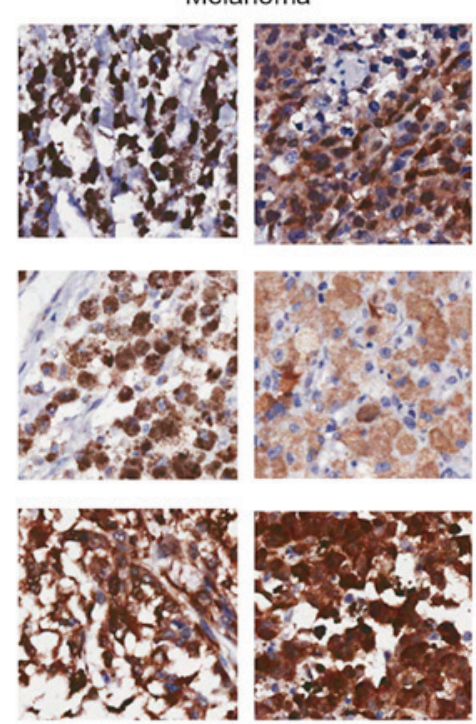

Figure 1.MSG1 expression is upregulated in malignant melanoma. (A) cDNA microarray analysis of the gene expression profile of human melanoma and paired nevus tissues. The upper left interspace indicates the genes upregulated in melanoma tissues, and the lower right interspace indicates the genes downregulated in melanoma tissues compared with nevus tissues. (B) The expression level of MSG1 mRNA was confirmed by reverse transcription-quantitative polymerase chain reaction. Data are presented as the mean \pm standard deviation $(\mathrm{n}=3) ;{ }^{* *} \mathrm{P}<0.01$ vs. nevus tissues. (C) IHC staining of $M S G 1$ in paired melanoma and nevus tissues from 6 out of 10 patients; representative images are shown. Magnification, x40. MSG1, melanocyte-specific gene 1; IHC, immunohistochemistry.

software (both from TissueGnostics, Vienna, Austria), and the images are presented in Fig. 1C.

Western blotting. Cells were lysed using Passive Lysis Buffer (Cell Signaling Technology, Inc., Danvers, MA, USA). Protein concentrations were measured using the BCA Protein Assay kit (Takara Bio., Inc.) and equal amounts of extracts $(30 \mu \mathrm{g})$ were subjected to SDS-PAGE (10\% gel), transferred onto a polyvinylidene fluoride membrane, and then blotted. The MSG1 antibody (cat no. ab87978) was purchased from Abcam. B-cell lymphoma 2 (Bcl-2; cat no. CST 2872) and $\beta$-actin (cat no. CST 3700) antibodies, all at a 1:1,000 dilution, and horseradish peroxidase-coupled secondary antibodies were purchased from Cell Signaling Technology, Inc. Antibody incubation was performed for $3 \mathrm{~h}$ at $4{ }^{\circ} \mathrm{C}$. At least 3 replicates were performed. Blocking was performed using tris-buffered saline with Tween-20, with $5 \%$ bovine serum albumin for $1 \mathrm{~h}$ at $20^{\circ} \mathrm{C}$. Imaging was performed using SuperSignal West Femto Maximum Sensitivity Substrate (Thermo Fisher Scientific, Inc.), and densitometric analysis was performed using Labworks Image Acquisition and Analysis Software (UVP, Upland, CA, USA).
Statistical analysis. Results are presented as the mean \pm standard deviation. Statistical analyses were performed using a Student's t-test. $\mathrm{P}<0.05$ was considered to indicate a statistically significant difference.

\section{Results}

MSG1 expression is upregulated in malignant melanoma. In order to determine the gene expression profile in malignant melanoma, a cDNA microarray was performed in the melanoma and paired nevus tissues, and the differential gene expression is presented in Fig. 1A. Among the differentially expressed genes, it was identified that the melanocyte differentiation-associated gene MSG1 was significantly upregulated in melanoma tissue compared with nevus tissue $(\mathrm{P}<0.01$; Fig. 1B). Additionally, the upregulation of MSG1 was confirmed by IHC in the melanoma tissues compared with nevus tissues (Fig. 1C). The results indicated that MSGl is upregulated in melanoma, and may potentially participate in melanoma carcinogenesis and progression.

MSG1 promotes cell viability in melanoma. As MSG1 was upregulated in melanoma, the roles of MSG1 in melanoma 
A
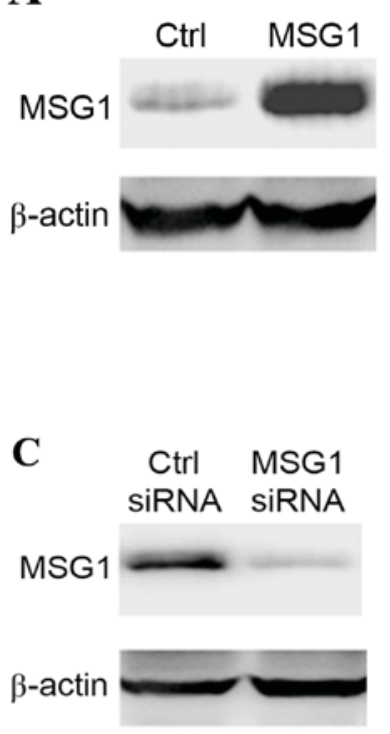
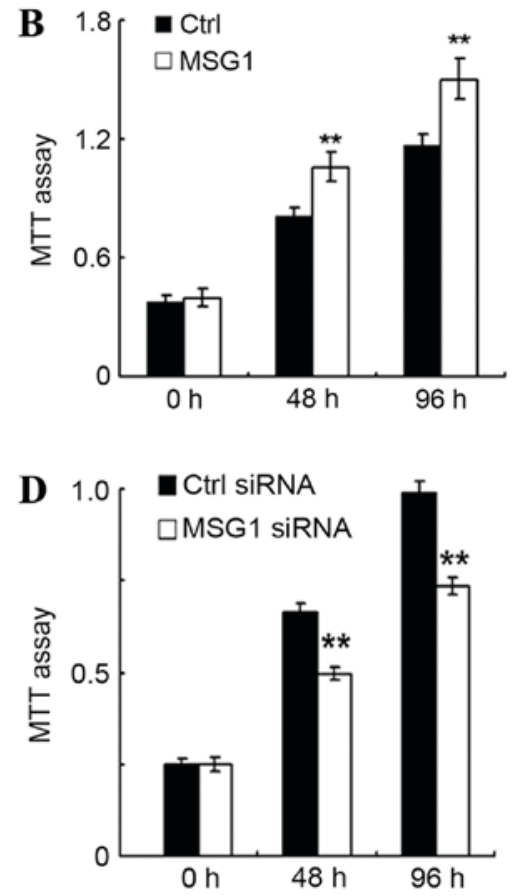

Figure 2. MSG1 promotes cell viability in malignant melanoma. (A) Increased MSG1 expression was confirmed by western blotting in A375 cells transfected with MSG1-expressing plasmids. (B) MTT cell viability analysis of A375 cells transfected with Ctrl or MSG1-expressing plasmids, at the indicated time points post-transfection. (C) Knockdown of MSG1 expression was confirmed by western blotting in A375 cells transfected with MSG1-specific siRNA. (D) MTT cell viability analysis of A375 cells transfected with Ctrl siRNA or MSG1-specific siRNA, at the indicated time points post-transfection. Quantified data are presented as the mean \pm standard deviation $(n=4)$; representative images are shown for the western blot results. ${ }^{* *} \mathrm{P}<0.01$ vs. corresponding Ctrl group at the same time point. MSG1, melanocyte-specific gene 1; Ctrl, control; siRNA, small interfering RNA.
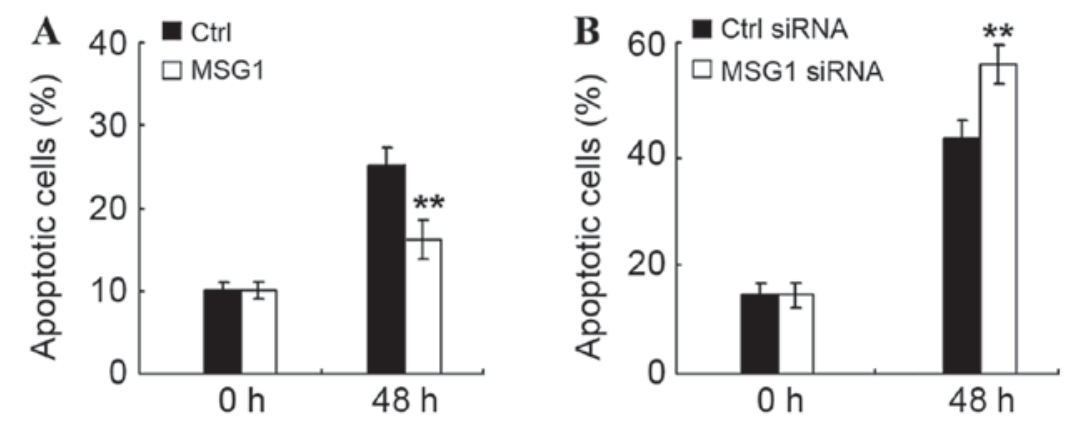

Figure 3. MSG1 inhibits cell apoptosis in malignant melanoma. Melanoma A375 cells were transfected with (A) Ctrl vectors or MSG1-expressing plasmids, (B) Ctrl siRNA or MSG1-siRNA as indicated. At the indicated time points post-serum deprivation, cell apoptosis was examined by Annexin V-propidium iodide staining and flow cytometric analysis. The Annexin V-positive cells were regarded as apoptotic cells. Data are presented as the mean \pm standard deviation $(n=4) .{ }^{* *} \mathrm{P}<0.01$ vs. corresponding Ctrl group at the same time point. MSG1, melanocyte-specific gene 1; Ctrl, control; siRNA, small interfering RNA.

development were further examined. The cell viability of melanoma A375 cells was examined in control-transfected or $M S G 1$-overexpressing cells, revealing that MSG1 overexpression could significantly increase cell viability in A375 cells $(\mathrm{P}<0.01$; Fig. $2 \mathrm{~A}$ and $\mathrm{B})$. In addition, this result was confirmed by the knockdown of MSG1 expression. Transfection of the A375 cells with an MSG1-specific siRNA significantly decreased the cell viability compared with the control-siRNA-transfected cells $(\mathrm{P}<0.01$; Fig. $2 \mathrm{C}$ and $\mathrm{D})$. Thus, it was concluded that overexpression of MSG1 in melanoma may increase cell viability.

MSG1 inhibits cell apoptosis in melanoma. In order to determine the mechanism of MSG1-promoted cell viability, the effect of MSG1 on cell apoptosis were additionally examined in melanoma cells. As demonstrated in Fig. 3A, MSG1 overexpression significantly inhibited cell apoptosis induced by serum deprivation $(\mathrm{P}<0.01)$, whereas knockdown of $M S G 1$ expression significantly promoted the serum deprivation-induced cell apoptosis ( $\mathrm{P}<0.01$; Fig. 3B). Therefore, $M S G 1$ may inhibit cell apoptosis of melanoma cells, thus enhancing cell viability and promoting melanoma progression.

MSG1 enhances anti-apoptotic Bcl-2 expression. The molecular mechanisms responsible for the inhibition of apoptosis mediated by MSG1 overexpression were explored. The expression of apoptosis-associated intracellular proteins in MSG1-overexpressing A375 cells were screened, and it was identified that the expression of the anti-apoptotic protein Bcl-2 was significantly increased by $M S G 1$ overexpression at the mRNA ( $\mathrm{P}<0.01$; Fig. 4A) and protein levels (Fig. 4B). 

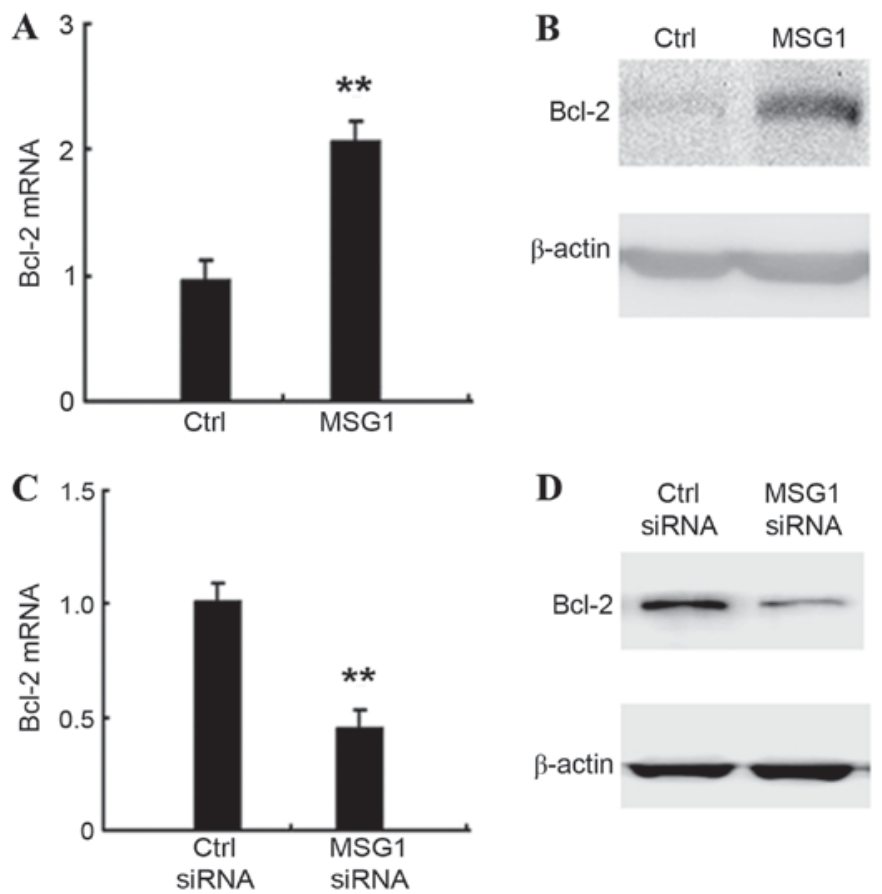

Figure 4. MSG1 enhances Bcl-2 expression in melanoma. (A and B) Melanoma A375 cells were transfected with a Ctrl vector or MSG1-expressing plasmids. MSG1 (A) mRNA and (B) protein levels were determined using RT-qPCR and western blot analysis, respectively, at $48 \mathrm{~h}$ post-transfection. (C and D) Melanoma A375 cells were transfected with Ctrl siRNA or MSG1-siRNA. MSG1 (C) mRNA and (D) protein levels were determined using RT-qPCR and western blot analysis, respectively, $48 \mathrm{~h}$ post-transfection. Quantified data are presented as the mean \pm standard deviation $(\mathrm{n}=4)$; representative images are shown for the western blot results. ${ }^{* *} \mathrm{P}<0.01$ vs. Ctrl group. MSG1, melanocyte-specific gene 1; Bcl-2, B-cell lymphoma 2; Ctrl, control; siRNA, small interfering RNA; RT-qPCR, reverse transcription-quantitative polymerase chain reaction.

Furthermore, the knockdown of MSG1 expression significantly inhibited the expression of Bcl-2 in A375 cells ( $\mathrm{P}<0.01$; Fig. 4C and D). Taken together, the results indicate that MSG1 may enhance the expression of anti-apoptotic Bcl-2, thus inhibiting cell apoptosis and promoting melanoma progression.

\section{Discussion}

In the present study, the gene expression profile in human melanoma tissues was screened using a cDNA microarray, and it was identified that the melanocyte differentiation-associated gene $M S G 1$ was significantly overexpressed in melanoma tissues. It was also identified that MSG1 may promote malignant melanoma progression by the inhibition of cell apoptosis, which is mediated by enhanced expression of anti-apoptotic Bcl-2. Therefore, these data suggest a novel molecular mechanism for malignant melanoma carcinogenesis and progression, which may suggest potential therapeutic strategies for the treatment of patients with melanoma.

The dysregulation of a set of genes has previously been identified in the carcinogenesis and progression of malignant melanoma, and several of these genes have been demonstrated to be correlated with the survival of melanoma patients (19-22). For example, caveolin-1 has been demonstrated to be upregulated in melanoma tissues, and correlated with melanoma metastasis and prognosis (23). In the present study, the upregulation of MSG1 was revealed to be associated with melanoma progression (23), but it remains unknown whether high $M S G 1$ expression in melanoma tissues predicts a poor survival time in patients with melanoma. Our future studies will further examine this issue in a larger cohort of patients with melanoma.
The promotion of cell viability and the inhibition of cell apoptosis are important aspects of cancer biology, and malignant melanoma has demonstrated a set of mechanisms for survival, including the inhibition of apoptosis and immune evasion (24-26). The present study indicated that expression of the important anti-apoptotic protein Bcl-2 is significantly induced by $M S G 1$ expression, and may contribute to the MSG1-mediated inhibition of apoptosis. However, the detailed mechanism responsible for the $M S G 1$-induced $\mathrm{Bcl}-2$ expression remains unknown. We hypothesized that MSG1 may enhance or participate in the initiation of Bcl-2 gene transcription, which requires additional investigation.

In conclusion, the upregulation of $M S G 1$ expression in melanoma tissues has been identified in the present study, suggesting that MSG1 may function as an oncogene in the carcinogenesis and progression of malignant melanoma. However, the detailed mechanism responsible for the upregulated expression of MSG1 in melanoma cells remains unknown. At present, genetic and epigenetic mechanisms have been identified to underlie the dysregulation of genes in cancer biology (19,27-29). We intend to investigate the detailed mechanism of the regulation of $M S G 1$ expression in melanoma cells, with the aim of elucidating the potential MSG1-mediated regulatory loop in melanoma development.

\section{Acknowledgements}

The authors would like to thank Dr Hao Zhang and Dr Hao Tang from Changhai Hospital (Shanghai, China) for their extensive assistance in the present project. The present study was supported by the Project of Shanghai Science and 
Technology Commission (grant no. 13JC1401403) and the SMMU Start-up Foundation for Youths (grant no. 2013QN08).

\section{References}

1. Siegel R, Ma J, Zou Z and Jemal A: Cancer statistics, 2014. CA Cancer J Clin 64: 9-29, 2014.

2. Siegel R, Naishadham D and Jemal A: Cancer statistics, 2012. Cancer J Clin 62: 10-29, 2012.

3. Balch CM, Gershenwald JE, Soong SJ, Thompson JF, Atkins MB, Byrd DR, Buzaid AC, Cochran AJ, Coit DG, Ding S, et al: Final version of 2009 AJCC melanoma staging and classification. J Clin Oncol 27: 6199-6206, 2009.

4. Ortega E, Marti RM, Yeramian A, Sorolla A, Dolcet X, Llobet D Abal L, Santacana M, Pallares J, Llombart-Cussac A and Matias-Guiu X: Targeted therapies in gynecologic cancers and melanoma. Semin Diagn Pathol 25: 262-273, 2008.

5. Terheyden P, Tilgen W and Hauschild A: Recent aspects of medical care of malignant melanoma. J Dtsch Dermatol Ges 6 868-878, 2008 (In English, German).

6. di Pietro A, Tosti G, Ferrucci PF and Testori A: Oncophage: Step to the future for vaccine therapy in melanoma. Expert Opin Biol Ther 8: 1973-1984, 2008.

7. Hou J, Zhou Y, Zheng Y, Fan J, Zhou W, Ng IO, Sun H, Qin L, Qiu S, Lee JM, et al: Hepatic RIG-I predicts survival and interferon- $\alpha$ therapeutic response in hepatocellular carcinoma. Cancer Cell 25: 49-63, 2014.

8. Hou J, Lin L, Zhou W, Wang Z, Ding G, Dong Q, Qin L, Wu X, Zheng Y, Yang Y, et al: Identification of miRNomes in human liver and hepatocellular carcinoma reveals miR-199a/b-3p as therapeutic target for hepatocellular carcinoma. Cancer Cell 19: 232-243, 2011.

9. Sumantran VN, Mishra P and Sudhakar N: Microarray analysis of differentially expressed genes regulating lipid metabolism during melanoma progression. Indian J Biochem Biophys 52: 125-131, 2015

10. Dadras SS, Lin RJ, Razavi G, Kawakami A, Du J, Feige E, Milner DA, Loda MF, Granter SR, Detmar M, et al: A novel role for microphthalmia-associated transcription factor-regulated pigment epithelium-derived factor during melanoma progression. Am J Pathol 185: 252-265, 2015.

11. Minca EC, Tubbs RR, Portier BP, Wang Z, Lanigan C, Aronow ME, Triozzi PL, Singh A, Cook JR, Saunthararajah Y, et al: Genomic microarray analysis on formalin-fixed paraffin-embedded material for uveal melanoma prognostication. Cancer Genet 207: 306-315, 2014.

12. Chiu CG, Nakamura Y, Chong KK, Huang SK, Kawas NP, Triche T, Elashoff D, Kiyohara E, Irie RF, Morton DL and Hoon DS: Genome-wide characterization of circulating tumor cells identifies novel prognostic genomic alterations in systemic melanoma metastasis. Clin Chem 60: 873-885, 2014.

13. Han B, Liu N, Yang X, Sun HB and Yang YC: MRG1 expression in fibroblasts is regulated by $\mathrm{Sp} 1 / \mathrm{Sp} 3$ and an Ets transcription factor. J Biol Chem 276: 7937-7942, 2001.
14. Yahata T, de Caestecker MP, Lechleider RJ, Andriole S, Roberts AB, Isselbacher KJ and Shioda T: The MSG1 non-DNA-binding transactivator binds to the p300/CBP coactivators, enhancing their functional link to the Smad transcription factors. J Biol Chem 275: 8825-8834, 2000.

15. Nair SS, Chaubal VA, Shioda T, Coser KR and Mojamdar M: Over-expression of MSG1 transcriptional co-activator increases melanin in B16 melanoma cells: A possible role for MSG1 in melanogenesis. Pigment Cell Res 14: 206-209, 2001.

16. Ahmed NU, Shioda T, Coser KR, Ichihashi M and Ueda M: Aberrant expression of MSG1 transcriptional activator in human malignant melanoma in vivo. Pigment Cell Res 14: 140-143, 2001.

17. Hou J, Wang P, Lin L, Liu X, Ma F, An H, Wang Z and Cao X: MicroRNA-146a feedback inhibits RIG-I-dependent Type I IFN production in macrophages by targeting TRAF6, IRAK1, and IRAK2. J Immunol 183: 2150-2158, 2009.

18. Livak KJ and Schmittgen TD: Analysis of relative gene expression data using real-time quantitative PCR and the 2(-Delta Delta C(T)) method. Methods 25: 402-408, 2001

19. Martinez-Cardús A, Vizoso M, Moran S and Manzano JL: Epigenetic mechanisms involved in melanoma pathogenesis and chemoresistance. Ann Transl Med 3: 209, 2015.

20. Elder DE: Pathology of melanoma. Surg Oncol Clin N Am 24: 229-237, 2015

21. Bartlett EK and Karakousis GC: Current staging and prognostic factors in melanoma. Surg Oncol Clin N Am 24: 215-227, 2015.

22. Higgins HW II, Lee KC, Galan A and Leffell DJ: Melanoma in situ: Part II. Histopathology, treatment, and clinical management. J Am Acad Dermatol 73: 193-203, 2015.

23. Stenzel M, Tura A, Nassar K, Rohrbach JM, Grisanti S, Lüke M and Lüke J: Analysis of caveolin-1 and phosphoinositol-3 kinase expression in primary uveal melanomas. Clin Experiment Ophthalmol 44: 400-409, 2016.

24. Talaiezadeh A, Jalali F, Galehdari H and Khodadadi A: Time depended Bcl-2 inhibition might be useful for a targeted drug therapy. Cancer Cell Int 15: 105, 2015.

25. Mukherjee N, Schwan JV, Fujita M, Norris DA and Shellman YG: Alternative treatments for melanoma: Targeting BCL-2 family members to De-Bulk and kill cancer stem cells. J Invest Dermatol 135: 2155-2161, 2015.

26. Hartman ML and Czyz M: Pro-survival role of MITF in melanoma. J Invest Dermatol 135: 352-358, 2015.

27. Brazel AJ and Vernimmen D: The complexity of epigenetic diseases. J Pathol 238: 333-344, 2016.

28. Ambrosone CB, Hong CC and Goodwin PJ: Host factors and risk of breast cancer recurrence: Genetic, epigenetic and biologic factors and breast cancer outcomes. Adv Exp Med Biol 862: 143-153, 2015.

29. Farooqi AA, Tang JY, Li RN, Ismail M, Chang YT, Shu CW, Yuan SS, Liu JR, Mansoor Q, Huang CJ and Chang HW: Epigenetic mechanisms in cancer: Push and pull between kneaded erasers and fate writers. Int J Nanomedicine 10: 3183-3191, 2015. 